\begin{tabular}{|l|l|}
\hline $\begin{array}{l}\text { Postprint } \\
\text { Version }\end{array}$ & 1.0 \\
\hline $\begin{array}{l}\text { Journal website } \\
\text { Pubmed link }\end{array}$ & $\underline{\text { http://sjp.sagepub.com/cgi/reprint/27/3/173 }}$ \\
\hline DOI & $\underline{\text { http://www.ncbi.nlm.nih.gov/pubmed/10482075? }}$ \\
\hline
\end{tabular}

This is a NIVEL certified Post Print, more info at http://www.nivel.eu

\title{
Medical practice variations: changing the theoretical approach
}

\author{
GERT P WESTERT ${ }^{1}$ AND PETER P GROENEWEGEN ${ }^{2}$ \\ ${ }^{1}$ National Institute of Public Health and The Environment (RIVM), \\ Department for Health Services Research, Bilthoven, ${ }^{2}$ Netherlands \\ Institute of Primary Health Care (NIVEL), Utrecht, The Netherlands \\ Variations in medical practice are well documented, but there has been less \\ progress in explaining these variations. This paper discusses the existing \\ theories and hypotheses and concludes that a change in theoretical approach is \\ required, to one that more directly highlights the social context influencing the \\ behaviour of doctors in their daily practice. An initial alternative model for \\ explaining variation in practice style is presented. The paper illustrates how \\ (combinations of) important structural factors, such as the availability of \\ hospital resources, the way the doctor is reimbursed, the availability of patients, \\ professional uncertainty, and the way the hospital is financed, lead to \\ hypotheses about when different local standards of medical care emerge. It is \\ concluded that theoretical progress in research on variations in medical practice \\ is possible and that empirical research needs to be driven by hypotheses that \\ emphasize the role of social contexts in the doctor's decision behaviour. Some \\ suggestions for future lines of research are outlined.
}

\section{INTRODUCTION}

"There is a city in Maine where the surgical procedure of hysterectomy was done so frequently in the past decade that if the rate persists, $70 \%$ of the women there will have had the operation by the time they reach the age of 75 . In a city less than 20 miles away the rate of hysterectomy is so much lower that if it persists, only $25 \%$ of the women will have lost their uterus by age 75." (1) Ever since Wennberg and Gittelsohn's seminal article in Science in 1973, geographical variation in common surgical procedures has been high on the research and policy agenda (1). Twenty-five years later it is known that the frequency of most types of medical interventions varies widely between geographical and organizational units at all levels of aggregation (2). A recent study, from July 1998, that documents variation in physician practice patterns describes results from the Maine Carpal Tunnel Study (3). Keller et al. demonstrate that carpal tunnel release rates across population-based service areas in the state of Maine, USA, varied 3.5-fold. The authors conclude, as Wennberg and Gittelsohn did 25 years ago, that "Among many potential factors influencingvariations, physician practice patterns appear to be the major contributor." (3).

Considerations of equity, efficiency, and effectiveness lie behind the widespread interest in health service variations among geographical areas. Ham concluded in his review of the literature (2): “Although considerable progress has been made in describing variations, 
Westert, G.P., Groenewegen, P.P. Medical practice variations: changing the theoretical approach. Scandinavian Journal of Public Health: 1999, 27(3), 173-180

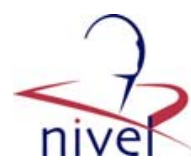

attempts at explanation have so far proved inconclusive or at least not susceptible to clearcut conclusions".

In 1993 Stano commented on the existing literature from theoretical and methodological points of view (4). He criticizes, in particular, the way in which the widely accepted practice style hypothesis of Wennberg is applied. According to the practice style hypothesis, variations in utilization rates arise from differences in clinical judgement among physicians as to the appropriate forms of treatment. The trouble with this hypothesis is, as Stano concludes, that it fails to distinguish practice style from other determinants of utilization. In empirical analyses there is often no clear distinction between variations among physicians in the application of medical procedures and population-based utilization rates. The first refers to one of the micro-level mechanisms producing variations, whilst the second refers to macro-level results of a number of different micro-level mechanisms. A different populationbased rate might, for instance, be the result of the same number of physicians applying an intervention at different rates, or a different number of physicians applying this intervention at the same rate. The methodological issues put forward by Stano (4) are the limited use of multivariate statistical techniques and the way most studies account for differences in case severity. Concerning statistical tools, much has changed in recent years (5).

We intend to follow the critical path along which Stano started before us. First, we discuss the existing explanations proposed for medical practice variations.

Many of the existing explanations imply that, in the end, variations are caused by differences in preferences among physicians about the appropriateness of practice styles. We illustrate this proposition in the next section. Secondly, we present an alternative explanatory approach that emphasizes the role of differences in opportunities, incentives, and influences, instead of in preferences. In the third section we use existing research findings and theoretical ideas that were introduced earlier as building blocks in the construction of an alternative hypothesis: within medical teams there is an (often implicit) idea of what should be done and how, and this shared (local) standard influences the choices made by individual physicians. This alternative originates in the borders between economics and sociology and it can be characterized as the social production function approach (6). We conclude with some lines of research to develop and test our ideas further.

\section{THE EXISTING EXPLANATORY APPROACH}

The existing explanatory work on variations in medical practice is rooted predominantly in a preference-oriented theoretical approach. This approach is based on the general statement that differences in behaviour between people can be explained by differences in their preferences for certain behaviour. The practice style hypothesis, the most commonly accepted hypothesis used to explain medical practice variations, is an example of this method of theoretical reasoning. The explanation of variations in medical procedures between areas or hospitals with the practice style hypothesis consists of two parts. The first part concerns the micro-level problem of the origins of widely differing practice styles among individual physicians. The second part concerns the explanation of differences between macro-level units, such as (small) geographical areas, hospitals or insurance plans. For the first part, it is supposed that physicians differ in the kind of procedures they apply, because they have somehow learned to value them differently and consequently adhere to a different practice style.

According to Wennberg and Gittelsohn, differences in practice style emerge because of uncertainty about the value of a certain level of medical care and of individual procedures (7). Hence, uncertainty within the profession differs between procedures, and this might explain why differences are larger for some procedures than for others $(8,9)$. Wennberg and Gittelsohn state that "in the absence of general agreement on their [the procedures] value for individual patients the style of practice of the individual takes precedence" (7). This implies 
that differences in practice style exist and come to the fore where there is not one generally accepted standard.

Alternatively, uncertainty is sometimes conceived of as a personality trait, in the sense that practice style variations are caused by differences between physicians in, for example, their tolerance of uncertainty (10). If physicians feel uncertain about how to proceed in a given case, and if they feel unhappy about that, they will try to reduce uncertainty. In the diagnostic phase, this would mean ordering more tests \pm although research on laboratory test ordering is equivocal on this hypothesis (11). In the therapeutic phase there is no general strategy, such as doing more, but only a situational strategy: do as your direct colleagues do. Eddy referred to this strategy as "the tendency to follow the pack" (12).

McClure, in his reconstruction of the practice style explanation, assumes that there is a broad range of acceptable styles of practice for which there are no clear differences in quality of care and outcomes (13).

Some of these styles will make conservative use of resources ("conservative styles"), others will have a high level of use of health care services ("elaborate styles").

For the second part of the explanation, the mechanism that propagates differences between areas or hospitals is the selective attraction or retention of physicians in the local medical system.

Wennberg and Gittelsohn point to this mechanism that causes the differences between areas: ' '... the rates of common surgical procedures constitute a `surgical signature' that tends to be consistent over many years, unless physicians leave the area or enter it." (7). In 1938, Glover referred to the same phenomenon in his discussion of area variation in tonsillectomy rates: "A large or sudden change [in surgery rates] usually denotes a change of medical officer \pm occasionally, increased facilities for operations." (14).

Chassin proposes the enthusiasm hypothesis: geographical differences in the application of certain interventions are caused by differences in the numbers of physicians who are enthusiastic about particular procedures (15). These differences might arise as a consequence of major local training programs for physicians. He developed this idea in a re-analysis of the Rand Health Services Utilization Study, by changing from population-based utilization rates to frequency of procedures per physician (16). In areas with high population-based utilization rates (of carotid endarterectomy, in this case) the density of surgeons was higher and the number of carotid endarterectomies per surgeon was much higher.

Specific support for the enthusiasm hypothesis is that areas with a high frequency of one procedure do not necessarily also have a high frequency of other procedures.

McClure has elaborated the second step of the practice style explanation, i.e. the mechanism of (self-) selection, by using a somewhat different approach (13). At the level of individual physicians, McClure argues from a preference-driven approach. Physicians differ in their preference for a certain practice style.

Because of the existence of a large "grey area" in medical decision-making, both conservative and elaborate practice styles can produce acceptable medical practice. Selective attraction or retention of physicians in the local medical system provides the mechanism to explain variations at higher levels of aggregation. McClure points to the external structure and incentives that influence the continued existence of health care organizations to explain why physicians with a more elaborate style of practice are attracted to hospitals or practices in certain areas. As an example: Health Maintenance Organizations attract or retain physicians with a conservative style of practice; if they do not, in a competitive environment, their costs will be too high, which translates into higher insurance premiums, fewer enrolees, and, eventually, the end of the organization. In conventional systems, however, where individual doctors or small groups are competing under fee-for-service conditions for their share of the market, physicians with an elaborate style of practice are attracted or retained. With respect to the diffusion of the prevailing style of practice, McClure adds that most responsible providers will not depart greatly from the acceptable area style because of professional incentives. 
In sum, both the practice style and the enthusiasm hypothesis assume that physicians have a preference for certain procedures. These differences originate somewhere during the educational history or practical experience of physicians. They come to the fore when uncertainty exists about the value of certain procedures or when doctors differ in their tolerance for uncertainty, and cluster together through (self) selection, as in the practice style hypothesis, or when influential educational programs have taken place in a region, as in the enthusiasm hypothesis.

The preference-centred approach stimulated patient outcome research. However, it does not shed much light on the behavioural mechanisms that produce different practice styles. The choice of this approach has the result that the social causes of differences in practice style are sought in the educational or practical experience history of doctors, in short their socialization history, or in differences in personality.

Two difficulties arise with the preference-centred approach. First, it is difficult to explain why physicians suddenly change their practice style, e.g.

after a change in payment system. Secondly, it is difficult to collect data on the origins of differences in preferences. As preferences are formed in the course of socialization and education, retrospective data collection has to go a long way back. The conclusion is not that preferences do not exist and do not influence people's behaviour, but that they cannot explain some important phenomena and they require data that are difficult to collect because of their retrospective nature. This makes a preference-centred approach less fruitful as a research strategy.

\section{AN ALTERNATIVE APROACH?}

An alternative to the preference-centred approach is the constraint-driven approach (6). This "depends on conditions approach" has as its starting point the general statement that preferences or practice styles are not so much caused by differences in tastes or pure preferences as by differences in characteristics of the social context (opportunities and constraints) that provide incentives for certain options or, alternatively, restrict people's behavioural choices. The emphasis on opportunities and constraints focuses attention on the social conditions that influence people's behaviour.

The social context in which physicians work differs between locations and this may consequently result in variations in medical practice styles (13).

Within a broader area of research, the economics of health care, numerous studies have appeared in which constraint-driven behavioural models have been used (17 \pm 19$)$. However, an application of such models to variations in medical practice is lacking.

Our method of theoretical model building goes back directly to microeconomics (6). Within the microeconomic tradition, it is usually assumed that in general people pursue two goals: money and leisure time. When empirical results depart from the model, other goals, such as adherence to medical ethics, are assumed post hoc, thereby missing a chance to generate and test new hypotheses. Therefore, we assume a different set of goals at a higher level of abstraction that allows the processing of a broader set of influences and gives a better description of reality.

To relate social conditions, such as institutional influences and incentives, to the options people choose, we conceive of people (physicians) as goal-oriented individuals who optimally gear their decisions (or practice style) to the realization of a few ultimate goals. Preferences within this approach can be seen as instrumental goals pursued in order to realize, within a certain constellation of opportunities and constraints, more general goals. Behaviour can therefore be predicted from the social conditions that influence the realization of instrumental goals.

Lindenberg, following Adam Smith, names two general goals, which are pursued by all individuals: physical well-being and social approval (6). Instrumental goals are seen as production factors for these general goals, hence the term “social production function 
Westert, G.P., Groenewegen, P.P. Medical practice variations: changing the theoretical approach. Scandinavian Journal of Public Health: 1999, 27(3), 173-180

approach". For example, under a system of fee-for-service payment performing more services is instrumental in gaining an income, which in turn is instrumental to people's physical well-being; under a salary system performing more services is not an instrumental goal that can be used to produce income.

Empirical research has shown that following a change in the payment system from capitation to fee-forservice, family physicians provided more services (20).

Instead of assuming a sudden change in preference, the social production function approach assumes that the constellation of incentives and influences has changed and that, consequently, performing more services has become an instrumental goal to reach the general and unchanged goals. Thus, according to Lindenberg's social production function approach, the preferences of individuals are explained in terms of the social structure, i.e. by the production conditions of a person's position in a given social context.

\section{ORIENTATION TOWARDS LOCAL STANDARDS}

The behavioural model behind the hypothesis of orientation towards local standards incorporates the existing hypotheses, developed by others, on "uncertainty", "enthusiasm", and "selection or retention of physicians". The basic building block of the model is that doctors conform to local standards in order to achieve their ultimate goals. In most cases these standards or norms are implicit and not explicitly formulated. Local standards of care develop at the level of groups of doctors who face the same mix of internal and external influences and incentives. The idea of conforming with local standards was developed by Westert in a study of variations in length of stay for surgical procedures between Dutch hospitals (21). As a first step in the explanation of length of stay variations it was assumed that the efforts of doctors in producing social approval will be directed towards maintaining previously attained social approval or minimizing the loss of social approval. As the medical specialist's work is predominantly teamwork, and people seek approval from others of higher or equal status, the main source of social approval is approval by direct colleagues. Doctors risk losing social approval if their medical performance is criticized by colleagues. To avoid this, a simple, but straightforward strategy is to "follow the pack" (12): social approval for an individual doctor is greater the less he or she deviates from what his or her colleagues usually do. If doctors follow this strategy, as we assume they do, local standards of medical care come into being within medical teams that share the same work environment.

Two predictions emerge from this basic idea. First, we expect that medical practice variations within a medical team, within hospitals (e.g. ENT groups), will be small compared with variations between teams.

Secondly, when a doctor works in different hospitals, and thus in different teams, with different local standards, he or she will conform to the usual practice in the hospital in which he or she is working in at that moment. Both predictions were confirmed empirically in a study on variations in length of hospital stay (22).

The confirmation of the second prediction is especially critical: where doctors work in different hospitals with different (procedure-specific) lengths of stay, intradoctor variation can be observed, that is to say that doctors choose a length of stay in the direction of the standard of the hospital in which they are working at the time. Arndt, Bradbury, and Golec recently showed that surgeons within medical teams do not vary in their policy on when it is appropriate to perform a hysterectomy, but between teams in different hospitals they observed large variations (23).

These findings provide some evidence to support the conclusion that the unit of analysis is individual doctors embedded within medical groups. The theoretical reason for this is that shared circumstances channel the behaviour of group members. Methodologically, this means that individual doctors are not independent units of analysis: individual practice styles show local patterns. 
The next question is how do differences in local standards among medical groups come about and how do they change over time? To make a start, we assume that groups of doctors develop local standards that optimize the achievement of their ultimate goals, subject to local restrictive circumstances. We propose five groups of important social factors: 1 . availability of hospital resources; 2. the way the doctor is reimbursed; 3 . availability of patients; 4. professional uncertainty; 5 . the way the hospital is financed.

Because the local circumstances of medical groups consist of a mix of interdependent factors, we will discuss three combinations: 1 and 2, 3 and 4, and, finally, 2 and 5, in order to illustrate how contextual influences in our theoretical approach lead to hypotheses about the emergence of different local standards of medical care.

\section{Availability of hospital resources and the way the doctor is reimbursed}

An obvious candidate for local restrictive circumstances is the availability of hospital beds, facilities, and medical personnel. There is a long range of studies, from the natural experiment described by Roemer to the comparisons of Boston and New Haven, indicating that a larger supply of hospital resources coincides with higher admission and readmission rates and longer lengths of hospital stay $(24,25)$. Evans connects this to clinical standards: $\because \ldots$

clinical standards are themselves malleable, and shift with the availability of resources" (26). The implication of this is that where the local supply of hospital beds, facilities, and medical staff is greater, local standards tend to be more elaborate. This phenomenon can be understood by connecting restrictive circumstances to the possibilities of the doctor's goalattainment.

Therefore, we assume that a doctor's physical wellbeing depends on a trade-off between income and leisure time. Whether and how doctors can optimize this trade-off depends heavily on the type of remuneration system (27). Fee-for-service payment produces different incentives than capitation or fixed salary payment. Now, suppose that the hospital has no budget cap and is financed per diem or per admission (we relax this assumption later) and the hospital resources (beds, facilities, and personnel) are abundant, we predict that a fee-forservices medical group develops local standards of care expressing higher levels of hospital utilization, compared with a medical group under capitation. If hospital beds, facilities, and medical personnel are in short supply, more services can be realized only by discharging patients earlier or by performing more services in outpatient clinics or day case surgery. However, there is, at least temporarily and at a given moment, a lower boundary to the length of hospitalization and the kind of services that can be performed in outpatient or day surgery. Even if it might be attractive from an income point of view to move beyond this boundary, the risk of losing one's colleagues' approval (and in some systems the risk of malpractice suits) is supposed to increase sharply. Under conditions of short supply and feefor-service payment, local standards tend to move towards this lower boundary. In the case of salaried doctors this move is less strong and waiting lists tend to develop (21).

Even the lower boundary itself might depend on local circumstances. Whether or not shorter hospital stays, outpatient or day surgery treatments, or less invasive treatment procedures are chosen depends on the degree of specialization of the doctors in the medical team involved and the level and quality of resources they have available. Apart from that, the availability of after-treatment care outside the hospital might affect what is locally possible in terms of lower boundaries.

\section{Availability of patients and professional uncertainty}

We will now illustrate how uncertainty or disagreement among doctors about "which rate is right" can be traced back to restrictive circumstances under which a doctor makes decisions (28). Let us assume that doctors receive a fee-for-services, that hospital resources are plentiful, but that patients are relatively scarce, because of high numbers of doctors per capita (e.g. urban areas with more than one hospital). In this situation we expect that doctors search for opportunities to attract more patients or to manipulate the existing patient flow. 
This is the situation typically described in the literature on supplier-induced demand. Rice defined supplier-induced demand as the extent to which a doctor "provides or recommends the provision of medical services that differ from what the patient would choose if he or she had available the same information and expertise as the physician" (29).

The extent to which doctors are able to manipulate demand depends (among other things) on the medical condition the patient presents. For some medical conditions the possible courses of action are clear and limited, whilst for others there is more room for discretion. The greater the room for discretion, the stronger the influence of non-medical circumstances, such as the system of remuneration, is on the course of action chosen. In other words, doctors are more tempted to induce patient demand for procedures for which there is uncertainty about how and when they should be performed. The latter factor is important because the opportunities for demand inducement are greater when "gold" standards are lacking and (hence) the chance of being criticized by colleagues in these cases is lower. Roos et al. found that the variation between areas, adjusted for mix in popula- tion characteristics, of surgical procedures without a "gold" standard was much larger, compared with procedures with well-defined diagnostic and therapeutic criteria (e.g. appendectomy, inguinal hernia repair) (8). The general prediction is, that under conditions of lower availability of patients and fee-for-service payment, local standards tend to favour higher rates of interventions and these local standards come to the fore more easily the more room for discretion the condition of the patient leaves.

The implication of this would be that all doctors in the same situation increase the same kinds of services.

However, another line of reasoning is possible if we assume that medical teams under conditions of scarcity of patients increase the scope of their services.

If doctors continue the path of medical specialization by building up unique skills in a limited number of medical problems or even in one (e.g. knee joints in the case of orthopaedic surgery), they increase the opportunities both to gain an income and to receive social approval of their direct colleagues. In this situation "surgical signatures", representing high levels of procedure-specific utilization, arise as a consequence of "medical hobbies", explored by doctors who try to attract more patients. This is consistent with Chassin's finding that "no significant correlation was found between the proportion of inappropriate cases and the population-based rate of use of the procedure among small areas" (15).

However, it also suggests that the hypothesis that professional enthusiasm for a specific type of medical treatment originates in major local physician training programs is incomplete, although it might be partly true. The additional, social context-driven hypothesis is that scarcity of patients encourages doctors to work on new techniques and skills that give them opportunities to attract more patients.

\section{Systems of hospital financing and the way the doctor is reimbursed}

Finally, we will look at the system of hospital financing in combination with the way the doctor is reimbursed. This combination of factors roughly divides the public health service systems (UK, Scandinavia) from the health systems with less state control and more influence from market forces (US, The Netherlands).

In general, doctors will take notice of the way the hospital is financed and try to incorporate the specific incentives in their medical practice. The argument for this is that doctors want to work in a financially healthy environment. This becomes a problem if the incentives that positively influence the doctor's income influence the hospital's budget negatively (or the other way around). The most problematic combination is fee-for-services for doctors and fixed yearly budgets for the hospital, as in The Netherlands. The combination of a fixed yearly budget for hospitals and fixed salaries for medical staff mainly causes problems for patients (UK, Scandinavia). Both actors involved have no incentive to prevent waiting lists: doctors are less prepared to give up leisure time and the hospital uses waiting lists as a political pawn in its yearly struggle with the health care authorities. 
In general, four basic systems of hospital financing can be observed nowadays: daily charge, global budgets, case payments or Diagnosis Related Group financing, and Comprehensive Health Care budgets, as in Health Maintenance Organisations (30).

If the hospital is paid a daily rate, practice styles that emphasize maximum utilization of bed days and lower admission rates are favourable. The fact that doctors incorporate the incentives that positively influence the hospitals' budget can be illustrated with an example from The Netherlands. Until the end of the 1980s the bed day was the major parameter for the calculation of the budget of the general hospitals. A few years ago the parameters were changed. The payment systems for doctors were left unchanged: fee-for-services in the majority of cases.

Among other things, the number of admissions, day treatments and outpatient department visits became relatively more important parameters. As a consequence of this the occupancy rates in Dutch general hospitals dropped (from 85\% in 1982) to almost 70\% in 1995.

Health care systems with capped global budgets and salaried medical personnel are among the first to encounter "problems" with waiting times for patients (as is witnessed in the UK and in Scandinavia).

Budget caps alone also seem to result in waiting lists for elective surgery. After a decade of budget caps in The Netherlands, waiting lists for surgery are a growing problem.

Under Diagnosis Related Group financing or case payments, practice styles that increase processing of patients or cases at lowest possible service intensity are more beneficial if the doctor is not on a salary contract. If, on the other hand, he or she is on a salary contract a similar organizational conflict occurs. The doctor's wish to slow down causes unexpected costs for the hospital management.

Health Maintenance Organisations, mostly combined with case payment financing, encourage the medical staff, either salaried or under fee-for-services, to follow a clinical strategy that emphasizes further rationing of the use of hospital resources per case, but that does not chase patients away.

Finally, independent of the hospital's financing system and the way the doctors are paid, the use of managed care and clinical guidelines by health care payers has a substantial impact on (variations in) service utilization. Maurer defined managed care as “... a comprehensive, united health system organized by the patient's healthcare payer and emphasizing quality while minimizing costs" (31). In situations of limited managed care penetration, doctors (and hospital managers) have more opportunities for supplier-induced demand than in situations of high penetration. It has been suggested that well-managed health care delivery systems can reduce hospital stays by approximately $40 \%(32,33)$.

\section{CONCLUSION}

Medical practice variations seem to follow clear local patterns. In our opinion these patterns can be explained by the social context influencing the work of medical teams. Our aim in this paper is to illustrate the productivity of this approach and its ability to incorporate existing ideas about why medical practice varies substantially between geographical units. Studies that systematically investigate the combined effect of the different types of interdependent influences on local medical practice are lacking.

Various (combinations of) factors/influences need to be considered if one wants to explain practice variations. Some of these influences will be measured at the patient level (e.g. case severity, co-payment) or the doctor level (e.g. payment system). Others are hospital or department characteristics (e.g. bed supply, hospital financing system). Sometimes regional characteristics need to be considered (e.g. alternative sources of care). In most cases we need international data from different health care systems, because otherwise there is not enough variation between "social contexts".

In our opinion the research agenda should contain the following issues: 1 . The question "which rate is right?", which is the main research question of the Patient Outcome Research 
Team, mentioned above, is less productive than the question "under what circumstances do doctors apply conservative practice styles instead of elaborate styles?" (15) 2. Studies evaluating different types of interventions to reduce existing practice style variations can be a valuable source of information to elaborate the latter and to detect what does and what does not affect physician behaviour $(34,35)$.

3. The finding that the medical practice of doctors is strongly influenced by what local peers are doing needs to be tested for different types of medical decision-making. Is the threshold for hospital admissions, the performance of surgical procedures or medical testing similar for individual doctors embedded in medical groups, as seemed to be the case for hospital lengths of stay? 4. Research that aims to find evidence-based standards of medical care should pay equal attention to the issue "which conditions influence the acceptance of 'gold' standards in daily medical practice?"

\section{REFERENCES}

1. Wennberg JE, Gittelsohn A. Small area variations in health care delivery. Science 1973; 183: $1102 \pm 8$.

2. Ham C. A review of the literature. In: Ham C, editor.

Health care variations; assessing the evidence. Research report no. 2. London: King's Fund Institute, 1988.

3. Keller RB, Largay AM, Soule DN, Katz JN. Maine Carpal Tunnel Study: small area variations. J Hand Surg 1998; 23: $692 \pm 6$.

4. Stano M. Evaluating the policy role of the small area variations and physician practice style hypotheses.

Health Policy 1993; 24: $9 \pm 17$.

5. Gatsonis CA, Epstein AM, Newhouse JP, Normand S, McNeil BJ. Variations in the utilisation of coronary angiography for elderly patients with an acute myocardial infarction. Med Care 1995; 33: $625 \pm 42$.

6. Lindenberg SM. Homo-socio economicus: the emergence of a general model of man in the social sciences.

J Inst Theoret Econ 1990; 146: $727 \pm 48$.

7. Wennberg JE, Gittelsohn A. Variations in medical care among small areas. Sci Am 1982; 246: $120 \pm 34$.

8. Roos NP, Wennberg JE, McPherson K. Using diagnosis-related groups for studying variations in hospital admissions. Health Care Financing Rev 1988; 9: $53 \pm 62$.

9. McPherson K. Variations in hospitalisation rates: why and how to study them. In: Ham C, editor. Health care variations; assessing the evidence. King's Fund Institute, research report No. 2. London: King's Fund Institute, 1988.

10. Gerrity MS, DeVellis RF, Earp JA. Physicians' reactions to uncertainty in patient care: a new measure and new insights. Med Care 1990; 28: $724 \pm 36$.

11. Zaat JOM. De macht der gewoonte. Amsterdam: Thesis, 1991.

12. Eddy D. Variations in physician practice: the role of uncertainty. Health Affairs 1986; 5: $74 \pm 89$.

13. McClure W. Toward development and application of a qualitative theory of hospital utilisation. Inquiry 1982; 19: $117 \pm 35$.

14. Glover JA. The incidence of tonsillectomy in school children. Proc Royal Soc Med 1938; 31: $1219 \pm 36$.

15. Chassin MR. Explaining geographic variations; the enthusiasm hypothesis. Med Care 1993; 31: YS37 \pm 44.

16. Leape LL, Park RE, Solomon DH, Chassin MR, Kosecoff J, Brook R. Relation between surgeon's practice volumes and geographic variation in the rate of carotid endarterectomy. N Engl J Med 1989; 321: $653 \pm 7$.

17. Evans RG. Supplier-induced demand: some empirical evidence and implications. In: M. Perlman, editor. The economics of health and medical care. London: Macmillan, 1974.

18. Pauly MV. Doctors and their workshops: economic models of physician behaviour. Chicago: University of Chicago Press for NBER, 1980. 
19. Eisenberg JM. Doctors' decisions and the cost of medical care. Michigan: Health Administration Press Perspectives, 1986.

20. Flierman HA. Changing the payment system of general practitioners. Utrecht: Nivel, 1991.

21. Westert GP. Variation in use of hospital care.

Maastricht: Van Gorcum, 1992.

22. Westert GP, Nieboer AP, Groenewegen PP. Variation in duration of hospital stay between hospitals and between doctors within hospitals. Soc Sci Med 1993; 37: $833 \pm 9$.

23. Arndt M, Bradbury RC, Golec J. Indications for hysterectomy: variation within and across hospitals.

Med Care Res Rev 1995; 52: $342 \pm 63$.

24. Roemer M. Bed supply and hospital utilisation: a natural experiment. Hospitals 1961; 35 : $209 \pm 16$.

25. Fisher ES, Wennberg JE, Stukel TA, Sharp SM.

Hospital readmission rates for cohorts of medicare benificiaries in Boston and New Haven. $\mathrm{N}$ Engl J Med 1994; 331: $989 \pm 95$.

26. Evans RG. The dog in the night-time: medical practice variations and health policy. In: Andersen TF, Mooney G, editors. The challenges of medical practice variations. London: Macmillan, 1990.

27. Delnoij DMJ. Physicians' payment systems and cost containment. Utrecht: Nivel, 1994.

28. Mooney G. Key issues in health economics. London: Harvester Wheatsheaf, 1994.

29. Rice TH. The impact of changing Medicare reimbursement rates on physician-induced demand. Med Care 1983; 21: $803 \pm 15$.

30. Glaser WA. Paying the hospital. London: Jossey Bass Publishers, 1987.

31. Maurer WJ. Understanding managed care. Wisconsin Med J 1988; 87: $31 \pm 2$.

32. Doyle RL. Healthcare management guidelines, volume 1: inpatient and surgical care. Milliman and Robertson: New York, 1992.

33. Aspling DL, Lagoe RJ. Development and implementation of a program to reduce hospital stays and manage resources on a community-wide basis. Nurs Admin Q 1995; 20: $1 \pm 11$.

34. Domenighetti G, Luraschi P, Casabianca A, Gutzwiller F, Spinelli A, Pedrinis E, et al. Effect of information campaign by the mass media on hysterectomy rates.

Lancet 1988; 2: 1470-3.

35. Lomas J, Anderson GM, Domnick-Pierre K, Vayda E, Enkin MW, Hannah WJ. Do practice guidelines guide practice? The effect of a consensus statement on the practice of physicians. N Engl J Med 1989; 321: $1306 \pm 11$. 